\title{
PENGARUH LINGKUNGAN KERJA, KOMPENSASI FINANSIAL DAN SEMANGAT KERJA TERHADAP KEPUASAN KERJA KARYAWAN PADA PT. USAHA GEDUNG MANDIRI DENPASAR BALI.
}

\author{
Kadek Sara Mandiyasa ${ }^{1}$, I Putu Mertha Darma Yasa ${ }^{2}$, Luh Putu Virra Indah Perdanawati ${ }^{3}$
}

Article history:

Submitted: 23 Desember 2020

Revised: 3 Januari 2021

Accepted:4 Februari 2021

\section{Keywords:}

Work Environment;

Financial Compensation;

Work Morale;

Job Satisfaction

\section{Kata Kunci:}

Lingkungan Kerja;

Kompensasi Finansial;

Semangat Kerja;

Kepuasan Kerja

\section{Koresponding:}

Fakultas Ekonomi dan Bisnis Universitas Ngurah Rai, Bali, Indonesia

Email:kadeksaramandiyasa@g mail.com ${ }^{1}$
Abstract

This study aims to determine the presence of positive and partial positive effects between the work environment, financial compensation and work morale on job satisfaction at PT. Usaha Gedung Mandiri Denpasar. This research was conducted at PT. Usaha Gedung Mandiri Denpasar. The technique for determining the number of samples in the study used saturated samples with a total sample of 82 employees. The results showed that 1) There was a positive influence simultaneously between the work environment, financial compensation and work morale on job satisfaction at PT. Usaha Gedung Mandiri Denpasar. 2) There is a partially positive effect between work environment on job satisfaction PT. Usaha Gedung Mandiri Denpasar. 3) There is a partially positive influence between financial compensation and job satisfaction at PT. Usaha Gedung Mandiri Denpasar. 4) There is a partially positive influence between work morale on job satisfaction at PT. Usaha Gedung Mandiri Denpasar.

\begin{tabular}{l} 
Abstrak \\
\hline Penelitian ini bertujuan untuk mengetahui adanya pengaruh yang \\
positif secara simultan dan parsial antara lingkungan kerja, kompensasi \\
finansial dan semangat kerja terhadap kepuasan kerja pada PT. Usaha \\
Gedung Mandiri Denpasar. Penelitian ini dilakukan pada PT. Usaha \\
Gedung Mandiri Denpasar. Adapun teknik penentuan jumlah sampel dalam \\
penelitian menggunakan sampel jenuh dengan jumlah sampel sebanyak 82 \\
orang karyawan. Hasil penelitian menunjukkan bahwa 1) Ada pengaruh \\
yang positif secara simultan antara lingkungan kerja, kompensasi finansial \\
dan semangat kerja terhadap kepuasan kerja pada PT. Usaha Gedung \\
Mandiri Denpasar. 2) Ada pengaruh yang positif secara parsial antara \\
lingkungan kerja terhadap kepuasan kerja pada PT. Usaha Gedung Mandiri \\
Denpasar. 3) Ada pengaruh yang positif secara parsial antara kompenasasi \\
finansial terhadap kepuasan kerja pada PT. Usaha Gedung Mandiri \\
Denpasar. 4) Ada pengaruh yang positif secara parsial antara semangat \\
kerja terhadap kepuasan kerja pada PT. Usaha Gedung Mandiri Denpasar.
\end{tabular}

Fakultas Ekonomi dan Bisnis Universitas Ngurah Rai, Bali, Indonesia ${ }^{2,3}$

Email: putumerthadarmayasa@gmail.com ${ }^{2}$ 


\section{PENDAHULUAN}

Banyak faktor yang mempengaruhi keberhasilan suatu organisasi. Salah satunya adalah karyawan, karena berkaitan langsung dengan kegiatan organisasi. Dalam hal ini karyawan diharapkan dapat memberikan hasil yang maksimal sehingga tujuan dari perusahaan atau organisasi dapat tercapai. Kepuasan kerja merupakan salah satu faktor bagi karyawan agar dapat bekerja secara maksimal. Dawal dan Taha (2006) menyatakan bahwa kepuasan kerja bagi karyawan merupakan kunci dari sehatnya sebuah organisasi. Sebuah perusahaan untuk dapat bertahan harus mempunyai karyawan yang memiliki sikap yang baik dan semangat kerja yang tinggi sehingga ada rasa kepuasan dan loyalitas terhadap perusahaan (Himawan, 2014).Lingkungan kerja merupakan salah satu faktor yang mempengaruhi kepuasan kerja pegawai. Jika dalam lingkungan sekitar tempat kerja memberikan kesan yang tidak nyaman, pegawai merasa malas untuk bekerja.

Permasalahan kepuasan kerja karyawan tidak terlepas dari apa yang diterima oleh karyawan itu sendiri. Faktor kompensasi finansial menjadi hal yang bisa mempengaruhi kepuasan kerja karyawan. Jika hak dari karyawan dapat terpenuhi kinerja karyawan juga akan meningkat yang menyebabkan tujuan dari perusahaan dapat tercapai. Menurut Yusnaena (2012) kompensasi finansial adalah imbalan atau balas jasa yang diberikan oleh organisasi atau perusahaan kepada para tenaga kerja karena tenaga kerja tersebut telah memberikan sumbangan tenaga dan pikiran demi kemajuan organisasi atau perusahaan guna mencapai tujuan.

Faktor terakhir yang mempengaruhi kepuasan kerja adalah semangat kerja. Semangat kerja adalah sesuatu yang membuat orang-orang senang mengabdi kepada pekerjaannya, dimana kepuasan bekerja dan hubungan-hubungan kekeluargaan yang menyenangkan menjadi bagian dari padanya. Semangat kerja juga merupakan reaksi emosional dan mental dari seseorang terhadap pekerjaannya. Semangat memengaruhi kuantitas dan kualitas pekerjaan seseorang (Purwanto, 2010). Jika semangat kerja tinggi, maka kinerja akan meningkat karena karyawan akan melakukan pekerjaannya secara lebih giat, akibatnya pekerjaan yang diharapkan lebih cepat dan lebih baik sehingga menimbulkan kepuasan dalam bekerja. Begitu juga sebaliknya jika semangat kerja menurun pula kepuasan kerja akan menurun.

PT. Usaha Gedung Mandiri Denpasar merupakan salah satu perusahaan pengisian ATM yang ada di Denpasar. Pembenahan di bidang sumber daya manusia khususnya dan pengembangan perusahaan pada umumnya terus dilakukan, karena salah satu unsur dalam manajemen adalah faktor sumber daya manusia (karyawan) yang ada dalam perusahaan. Berdasarkan hasil observasi sebelumnya pada karyawan PT. Usaha Gedung Mandiri Denpasar, masih ada karyawan yang merasakan ketidakpuasan dalam bekerja dikarenakan hubungan dengan rekan kerja tidak berjalan dengan baik mengakibatkan terjadinya konflik antara sesama rekan kerja, imbalan yang diberikan perusahaan tidak sesuai dengan beban kerja yang diterima, kurangnya motivasi atasan kepada karyawan dalam menyelesaikan pekerjaan, tidak adanya koordinasi antara rekan kerja dalam menyelesaikan pekerjaannya, dan gaji yang diterima terkadang tidak tepat waktu. Selain itu, kepuasan kerja karyawan juga dipengaruhi oleh faktor lingkungan kerja, kompensasi finansial dan semangat kerja karyawan.

Berdasarkan observasi ditemui fenomena bahwa permasalahan lingkungan kerja non fisik yang dijumpai pada PT. Usaha Gedung Mandiri Denpasar, diantaranya adalah dalam hal kerjasama antar sesama rekan kerja masih belum maksimal, terlihat dari masih adanya karyawan yang lebih suka bekerja secara individu daripada harus bekerja bersama, ini akan memberikan pengaruh terhadap kinerja yang akan dihasilkan. Padahal kerjasama dalam tim kerja harusnya menjadi sebuah kebutuhan dalam mewujudkan keberhasilan kinerja dan prestasi kerja. Selain kondisi non fisik lingkungan kerja, kondisi fisik yang belum tertata rapi serta ruang kerja yang masih belum kondusif dinilai sebagai faktor

Pengaruh Lingkungan Kerja, Kompensasi Finansial dan Semangat Kerja Terhadap Keputusan Kerja Karyawan Pada PT. Usaha Gedung Mandiri Denpasar Bali 
penghambat dalam meningkatkan kepuasan kerja karyawan. Tempat kerja yang kurang nyaman, sirkulasi udara yang kurang begitu baik, dan ukuran ruangan yang kurang luas.

Selain masalah lingkungan kerja, kompensasi juga menjadi salah satu faktor yang mempengaruhi kepuasan kerja. Kompensasi finansial yang diterima antar karyawan berbeda-beda tergantung pada jabatan dan lamanya bekerja. Berdasarkan wawancara yang dilakukan dengan karyawan, kompensasi finansial yang diterima berupa gaji, uang makan, uang lembur, tunjangan ketenagakerjaan dan tunjangan kesehatan. Pemberian kompensasi finansial bagi karyawan diatur dalam surat perjanjian yang telah disepakati antara pihak PT. Usaha Gedung Mandiri Denpasar dengan karyawan yang bersangkutan. Namun bagi karyawan dengan jam kerja selama 12 jam yang terdiri dari 8 jam kerja efektif ditambah 4 jam lembur serta beban kerja yang mereka terima itu tidak sepadan dengan jumlah Upah Minimum Kabupaten (UMK) yang telah ditetapkan pemerintah.

Berdasarkan observasi dilapangan, jumlah kompensasi finansial yang diterima menunjukkan ketidaksesuaian antara beban kerja dengan gaji yang diterima, perusahan yang tidak memberikan uang transport bagi kayawan yang diberi tugas keluar serta gaji yang diterima kadang tidak tepat waktu. Keadaan tersebut pada akhirnya menyebabkan berkurangnya kepuasan kerja mereka untuk meningkatkan kinerja, dan selanjutnya berdampak terhadap tidak meningkatnya kinerja perusahaan secara keseluruhan.

Faktor terakhir yang mempengaruhi kepuasan kerja adalah semangat kerja. Berdasarkan hasil observasi sebelumnya pada karyawan PT. Usaha Gedung Mandiri Denpasar, ditemukan kurangnya kerjasama dan saling membantu antara karyawan dalam menyelesaikan pekerjaan, kurang inisiatifnya karyawan dalam memperbaiki kesalahan dalam bekerja serta kurang semangatnya karyawan dalam bekerja. Salah satu indikator baik tidaknya semangat kerja karyawan dapat dilihat dari tingkat absensi karyawannya. Dari data yang diperoleh dapat diidentifikasi suatu permasalahan bahwa menurunnya semangat kerja karyawan yang ditandai dengan adanya kecenderungan (trend) meningkatnya absensi karyawan, dimana persentase tingkat absensi karyawan rata-rata sebesar 3,06 persen, hal ini berarti bahwa tingkat absensi karyawan tergolong tinggi. Tingkat absensi menggambarkan tingkat ketidak hadiran pegawai serta mencerminkan tingkat disiplin kerja karyawan disuatu perusahaan. Hal ini perlu mendapat perhatian serius dari pihak pimpinan. Dengan memperhatikan tingkat absensi karyawan, maka dapat diketahui bahwa semakin tinggi tingkat absensi karyawan, menunjukkan rendahnya semangat kerja karyawan (Tohardi, 2008). Selain itu semangat kerja karyawan pada PT. Usaha Gedung Mandiri Denpasar dilihat dari kurangnya antusiasme karyawan dalam bekerja dan kurangnya kerjasama antar rekan kerja dalam menyelesaikan pekerjaan.

Berdasarkan fakta yang diperoleh dari PT. Usaha Gedung Mandiri Denpasar tentang adanya beberapa karyawan yang memiliki kepuasan kerja yang rendah, lingkungan kerja yang tidak kondusif, kompensasi finansial yang tidak sesuai dengan pekerjaannya, dan semangat kerja yang menurun, maka alasan tersebut yang mendasari penelitian ini mengambil judul Pengaruh Lingkungan Kerja, Kompensasi Finansial Dan Semangat Kerja Terhadap Kepuasan Kerja Karyawan Pada PT. Usaha Gedung Mandiri Denpasar Bali. Penelitian ini bertujuan untuk mengetahui adanya pengaruh yang positif secara simultan dan parsial antara lingkungan kerja, kompensasi finansial dan semangat kerja terhadap kepuasan kerja pada PT. Usaha Gedung Mandiri Denpasar.

\section{METODE PENELITIAN}

Desain penelitian yang digunakan dalam penelitian ini adalah penelitian kuantitatif. Populasi dalam penelitian ini adalah karyawan pada PT. Usaha Gedung Mandiri Denpasar yang berjumlah 82 Pengaruh Lingkungan Kerja, Kompensasi Finansial dan Semangat Kerja Terhadap Keputusan Kerja Karyawan Pada PT. Usaha Gedung Mandiri Denpasar Bali 
orang karyawan. Sampel yang dapat diambil dalam penelitian ini adalah sebanyak 82 orang responden. Dalam penelitian ini penentuan sampel menggunakan metode teknik non probability sampling yaitu teknik sampel jenuh. Teknik pengumpulan data dalam penelitian ini dilakukan dengan observasi, wawancara, studi dokumentasi dan metode kuesioner (angket). Setiap jawaban kuesioner mempunyai bobot atau skor nilai dengan skala Likert sebagai berikut: Sangat Tidak Setuju (STS) = skor 1, Tidak Setuju $(\mathrm{TS})=$ skor 2, Kurang Setuju $(\mathrm{KS})=$ skor 3, Setuju $(\mathrm{S})=$ skor 4 dan Sangat Setuju $(\mathrm{SS})=$ skor 5 . Teknik analisis data dalam penelitian ini menggunakan pendekatan kuantitatif yaitu analisis statistik inferensial, terdiri dari: uji asumsi klasik, analisis regresi linier berganda, analisis determinasi, uji signifikansi simultan (uji statistik F) dan uji signifikansi parameter individual (uji statistik t).

\section{HASIL DAN PEMBAHASAN}

Text Hasil Uji Validitas dan Reliabilitas Instrumen Penelitian Uji Validitas Instrumen Penelitian Hasil pengujian diperoleh sebagai berikut:

Tabel 1

Hasil Pengujian Validitas

\begin{tabular}{|c|c|c|c|c|}
\hline $\begin{array}{c}\text { Variabel } \\
\text { (1) }\end{array}$ & $\begin{array}{l}\text { Kode } \\
(2)\end{array}$ & $\begin{array}{l}\text { Koefisien Korelasi } \\
\text { (3) }\end{array}$ & $\begin{array}{l}\text { Nilai } r_{\text {tabel }} \\
\text { (4) }\end{array}$ & $\begin{array}{l}\text { Keterangan } \\
\text { (5) }\end{array}$ \\
\hline \multirow{10}{*}{$\begin{array}{l}\text { Lingkungan Kerja } \\
\left(\mathrm{X}_{1}\right)\end{array}$} & Lingkungan_kerja_1 & 0,814 & 0,30 & Valid \\
\hline & Lingkungan_kerja_2 & 0,795 & 0,30 & Valid \\
\hline & Lingkungan_kerja_3 & 0,795 & 0,30 & Valid \\
\hline & Lingkungan_kerja_4 & 0,850 & 0,30 & Valid \\
\hline & Lingkungan_kerja_5 & 0,877 & 0,30 & Valid \\
\hline & Lingkungan_kerja_6 & 0,881 & 0,30 & Valid \\
\hline & Lingkungan_kerja_7 & 0,868 & 0,30 & Valid \\
\hline & Lingkungan_kerja_8 & 0,836 & 0,30 & Valid \\
\hline & Lingkungan_kerja_9 & 0,806 & 0,30 & Valid \\
\hline & Lingkungan_kerja_10 & 0,796 & 0,30 & Valid \\
\hline Kompensasi & Kompensasi_finansial_1 & 0,795 & 0,30 & Valid \\
\hline \multirow[t]{5}{*}{ Finansial $\left(\mathrm{X}_{2}\right)$} & Kompensasi_finansial_2 & 0,875 & 0,30 & Valid \\
\hline & Kompensasi_finansial_3 & 0,883 & 0,30 & Valid \\
\hline & Kompensasi_finansial_4 & 0,909 & 0,30 & Valid \\
\hline & Kompensasi_finansial_5 & 0,866 & 0,30 & Valid \\
\hline & Kompensasi_finansial_6 & 0,836 & 0,30 & Valid \\
\hline \multirow[t]{4}{*}{ Semangat Kerja $\left(\mathrm{X}_{3}\right)$} & Semangat_kerja_1 & 0,919 & 0,30 & Valid \\
\hline & Semangat_kerja_2 & 0,914 & 0,30 & Valid \\
\hline & Semangat_kerja_3 & 0,934 & 0,30 & Valid \\
\hline & Semangat_kerja_4 & 0,948 & 0,30 & Valid \\
\hline \multirow[t]{5}{*}{ Kepuasan Kerja (Y) } & Kepuasan_kerja_1 & 0,615 & 0,30 & Valid \\
\hline & Kepuasan_kerja_2 & 0,652 & 0,30 & Valid \\
\hline & Kepuasan_kerja_3 & 0,639 & 0,30 & Valid \\
\hline & Kepuasan_kerja_4 & 0,758 & 0,30 & Valid \\
\hline & Kepuasan_kerja_5 & 0,715 & 0,30 & Valid \\
\hline
\end{tabular}

Sumber: data diolah, tahun 2020

Pada Tabel 1, menunjukkan bahwa semua indikator yang digunakan untuk mengukur variabel-variabel yang digunakan dalam penelitian ini mempunyai koefisien korelasi yang lebih besar 
dari r-tabel (nilai r-tabel sebesar 0,30). Sehingga semua indikator dari variabel penelitian ini adalah valid.

Tabel 2

Hasil Pengujian Reliabilitas

\begin{tabular}{lcc}
\hline \multicolumn{1}{c}{ Variabel } & Nilai Hitung Alpha Cronbach & Keterangan \\
\multicolumn{1}{c}{$(1)$} & $(2)$ & $(3)$ \\
\hline Lingkungan kerja $\left(\mathrm{X}_{1}\right)$ & 0,950 & Reliabel \\
Kompensasi finansial $\left(\mathrm{X}_{2}\right)$ & 0,925 & Reliabel \\
Semangat kerja $\left(\mathrm{X}_{3}\right)$ & 0,945 & Reliabel \\
Kepuasan kerja $(\mathrm{Y})$ & 0,703 & Reliabel \\
\hline
\end{tabular}

Sumber: Data diolah, 2020.

Suatu konstruk atau variabel dikatakan reliabel jika memberikan nilai Cronbach Alpha > 0,70 (Sugiyono, 2013:168). Pada Tabel 2 menunjukan bahwa setiap variabel yang digunakan dalam penelitian ini dinyatakan reliabel. Uji asumsi klasik digunakan untuk mengetahui kelayakan penggunaan model regresi.

Tabel 3

Hasil Uji Multikolinearitas

\begin{tabular}{lcc}
\hline \multicolumn{1}{c}{ Variabel Bebas } & Collinearity Statistic & TIF \\
\hline Lingkungan Kerja $\left(\mathrm{X}_{1}\right)$ & 0,796 & 1,256 \\
Kompensasi Finasial $\left(\mathrm{X}_{2}\right)$ & 0,776 & 1,289 \\
Semangat Kerja $\left(\mathrm{X}_{3}\right)$ & 0,897 & 1,114 \\
\hline
\end{tabular}

Sumber: Olah data SPSS version 19.0 for windows, tahun 2020

Berdasarkan Tabel 3 dapat disimpulkan bahwa model regresi layak dipakai dalam penelitian ini karena syarat untuk tidak terjadi multikolonieritas sudah dipenuhi yakni nilai tolerance $>0,10$ atau sama dengan nilai VIF <10. Oleh karena itu berdasarkan uji heteroskedastisitas menggunakan metode analisis grafik, pada model regresi yang terbentuk dinyatakan tidak terjadi gejala heteroskedastisitas. Hasil uji normalitas dapat dilihat pada Tabel 4.

Tabel 4

Hasil Uji Normalitas dengan Uji Kolmogorov-Smirnov

\begin{tabular}{lc}
\hline & Unstandardized Residual \\
\hline $\mathrm{N}$ & 82 \\
Kolmogorov-Smirnov Z & 0,826 \\
Aymp. Sig (2-tailed) & 0,503 \\
\hline
\end{tabular}

Sumber: Olah data SPSS version 19.0 for windows, tahun 2020

Berdasarkan Tabel 4 dapat diketahui bahwa besarnya nilai kolmogorov smirnov yaitu sebesar 0,826. Hasil Asym. Sig diperoleh sebesar 0,503 hasil ini dibandingkan dengan probabilitas

Pengaruh Lingkungan Kerja, Kompensasi Finansial dan Semangat Kerja Terhadap Keputusan Kerja Karyawan Pada PT. Usaha Gedung Mandiri Denpasar Bali Kadek Sara Mandiyasa, I Putu Mertha Darma Yasa dan Luh Putu Virra Indah Perdanawati 
0,05 maka lebih besar, sehingga dapat disimpulkan bahwa data penelitian berdistribusi secara normal. Analisis Regresi Linier Berganda Hasil analisis regresi linier berganda dapat dilihat pada Tabel 5.

Tabel 5

Rekapitulasi Hasil Analisis Regresi Linier Berganda

\begin{tabular}{lrrr}
\hline \multicolumn{1}{c}{ Variabel } & \multicolumn{2}{c}{ Unstandardized Coefficients } \\
& $\mathrm{B}$ & \multicolumn{2}{c}{ Standard Error } \\
\hline Konstanta & & 7,900 & 0,962 \\
Lingkungan Kerja $\left(\mathrm{X}_{1}\right)$ & & 0,113 & 0,021 \\
Kompensasi Finansial $\left(\mathrm{X}_{2}\right)$ & 0,190 & 0,031 \\
Semangat Kerja $\left(\mathrm{X}_{3}\right)$ & 0,236 & 0,034 \\
\hline
\end{tabular}

Sumber: Olah data SPSS version 19.0 for windows, tahun 2020

Berdasarkan Tabel 5 diperoleh persamaan regresi linier berganda adalah : $\mathrm{Y}=7,900+0,113$ $\mathrm{X} 1+0,190 \mathrm{X} 2+0,236 \mathrm{X} 3$ sehingga memberikan informasi bahwa: $\mathrm{a}=7,900$ artinya bahwa apabila tidak ada perhatian terhadap lingkungan kerja, kompensasi finansial dan semangat kerja atau nilainya adalah konstan, maka kepuasan kerja adalah sebesar rata-rata 7,900. b1 $=0,113$ artinya apabila variabel kompensasi finansial (X2) dan semangat kerja (X3) dianggap konstan, maka meningkatnya sekor lingkungan kerja (X1) sebesar satu satuan akan diikuti oleh meningkatnya kepuasan kerja sebesar rata-rata 0,113 . b2 $=0,190$ artinya apabila variabel lingkungan kerja (X1) dan semangat kerja (X3) dianggap konstan, maka meningkatnya sekor kompensasi finansial (X2) sebesar satu satuan akan diikuti oleh meningkatnya kepuasan kerja sebesar rata-rata 0,190 . b3 $=0,236$ artinya apabila variabel lingkungan kerja (X1) dan kompensasi finansial (X2) dianggap konstan, maka meningkatnya sekor semangat kerja (X3) sebesar satu satuan akan diikuti oleh meningkatnya kepuasan kerja sebesar ratarata 0,236 .

Tabel 6

Tabel Model Summary

\begin{tabular}{ccc}
\hline Model & $\mathrm{R}$ & $\mathrm{R}$ Square \\
\hline 1 & 0,821 & 0,674
\end{tabular}

Sumber: Olah data SPSS version 19.0 for windows, tahun 2020

Berdasarkan Tabel 6 diketahui besarnya koefisien determinasi adalah sebesar D =67,40\%. Hal ini berarti bahwa besarnya kontribusi/sumbangan lingkungan kerja, kompensasi finansial dan semangat kerja terhadap kepuasan kerja pada PT. Usaha Gedung Mandiri Denpasar adalah sebesar $67,40 \%$ sedangkan sisanya sebesar 32,60\% dipengaruhi oleh faktor-faktor lain yang tidak di bahas.

Berdasarkan hasil analisis regresi linier berganda menunjukkan bahwa nilai F-hitung adalah sebesar 53,634 lebih besar dari pada nilai F-tabel = 2,72 maka H0 ditolak dan Ha diterima. Hal ini berarti bahwa ada pengaruh yang positif secara simultan antara lingkungan kerja, kompensasi finansial dan semangat kerja terhadap kepuasan kerja pada PT. Usaha Gedung Mandiri Denpasar. Berdasarkan hasil uji regresi parsial menunjukkan bahwa nilai t-hitung diperoleh sebesar 5,396 sedangkan nilai ttabel sebesar 1,665. Ternyata nilai t1-hitung lebih besar dari pada nilai t-tabel atau t-hitung $=5,396$ > $\mathrm{t}$-tabel $=1,665$. Maka kesimpulannya bahwa H0 ditolak dan Ha diterima. Artinya bahwa ada pengaruh yang positif secara parsial antara lingkungan kerja (X1) terhadap kepuasan kerja (Y) pada PT. Usaha Gedung Mandiri Denpasar. Serta untuk variabel kompensasi financial nilai t2-hitung diperoleh sebesar 
6,096 sedangkan nilai t-tabel sebesar 1,665. Ternyata nilai t2-hitung lebih besar dari pada nilai t-tabel atau t2-hitung $=6,096>$ t-tabel $=1,665$. Maka kesimpulannya bahwa H0 ditolak dan Ha diterima. Artinya bahwa ada pengaruh yang positif secara parsial antara kompenasasi finansial (X2) terhadap kepuasan kerja (Y) pada PT. Usaha Gedung Mandiri Denpasar. Berdasarkan hasil uji parsial, variable semangat kerja menunjukkan bahwa nilai t3-hitung diperoleh sebesar 6,869 sedangkan nilai t-tabel sebesar 1,665. Ternyata nilai t3-hitung lebih besar dari pada nilai t-tabel atau t3-hitung $=6,869>\mathrm{t}$ tabel $=1,665$. Maka kesimpulannya bahwa H0 ditolak dan Ha diterima. Artinya bahwa ada pengaruh yang positif secara parsial antara semangat kerja (X3) terhadap kepuasan kerja (Y) pada PT. Usaha Gedung Mandiri Denpasar.

\section{SIMPULAN DAN SARAN}

Berdasarkan analisa dan data-data diatas menunjukkan bahwa ada pengaruh yang positif secara simultan antara lingkungan kerja, kompensasi finansial dan semangat kerja terhadap kepuasan kerja pada PT. Usaha Gedung Mandiri Denpasar, serta dapat disimpulkan bahwa hipotesis dalam penelitian ini diterima. Dengan meningkatkan lingkungan kerja, kompensasi finansial dan semangat kerja maka akan berpengaruh terhadap kepuasan kerja. Berdasarkan pembahasan bahwa hipotesis dalam penelitian ini diterima yang artinya ada pengaruh yang positif secara parsial antara lingkungan kerja (X1) terhadap kepuasan kerja (Y) pada PT. Usaha Gedung Mandiri Denpasar. Berdasarkan pembahasan bahwa hipotesis dalam penelitian ini diterima yang artinya ada pengaruh yang positif secara parsial antara kompenasasi finansial (X2) terhadap kepuasan kerja (Y) pada PT. Usaha Gedung Mandiri Denpasar. Berdasarkan pembahasan bahwa hipotesis dalam penelitian ini diterima yang artinya ada pengaruh yang positif secara parsial antara semangat kerja (X3) terhadap kepuasan kerja (Y) pada PT. Usaha Gedung Mandiri Denpasar.

Saran yang dapat diberikan yakni pimpinan PT. Usaha Gedung Mandiri Denpasar perlu untuk memperbaiki hubungan antara karyawan dan sering melakukan komunikasi dengan karyawan agar dapat meningkatkan kepuasan kerja karyawan. Perusahaan hendaknya memberikan perhatian dalam hal pemberian tunjangan transport kepada karyawan yang tugas keluar. Diharapkan kepada seluruh karyawan lebih meningkatkan kerja sama antar team agar pekerjaan dapat terselesaikan dengan baik karena masih adanya karyawan yang lebih suka bekerja secara individu daripada harus bekerja bersama. Perusahaan hendaknya memperhatikan imbalan yang diberikan dengan beban kerja karyawan, karena beban kerja yang mereka terima itu tidak sepadan dengan jumlah Upah Minimum Kabupaten (UMK) yang telah ditetapkan pemerintah.

\section{REFERENSI}

Alex, N., S. (2002). Manajemen Personalia: Manajemen Sumber Daya Manusia. Edisi 3. Jakarta: Ghalia Indonesia.

Akbar dan Usman. (2009). Metode Penelitian Sosial. Jakarta: Bumi Aksara.

Amalia, R. (2012). Pengaruh Budaya Organisasi dan Kepuasan Kerja terhadp Kinerja KAryawan Melalui Kepuasan Kerja sebagai Variabel Intervening. Skripsi. Universitas Negeri Padang.

Arikunto, S. (2010). Prosedur Penelitian: Suatu Pendekatan Praktik. Edisi Revisi VI. Jakarta: PT. Rineka Cipta. Darmawan, D. (2014). Prinsip-Prinsip Perilaku Organisasi. Surabaya: Pena Semesta.

Dawal, and Zahari, T. (2006). The Effect of Job and Environmental Factor on Job Statisfacation in Automative Industries. Internasional Journal of Occupational Safety and Ergonomics (JOSE). 12(13), 267-280.

Dessler, G. (2015). Manajemen Sumber Daya Manusia. Jakarta: Salemba Empat.

Pengaruh Lingkungan Kerja, Kompensasi Finansial dan Semangat Kerja Terhadap Keputusan Kerja Karyawan Pada PT. Usaha Gedung Mandiri Denpasar Bali 
Gorda, I Gusti Ngurah. (2006). Manajemen Sumber Daya Manusia. Cetakan Ketiga. Denpasar: Astabrata Bali.

Hendri, Edduar. (2010). Pengaruh Semangat Kerja Terhadap Kinerja Pegawai Fakultas Ekonomi Universitas Negeri Palembang. Jurnal Media Wahana Ekonomika. 7(2), 13-25.

Himawan, C., H. (2014). Pengaruh Lingkungan Kerja dan Kompensasi Terhadap Kepuasan Kerja Karyawan Pabrik Genteng Massokka Kebumen, Jawa Tengah. Skripsi. Yogyakarta: Universitas Negeri Yogyakarta.

Kusumah, D., H. (2016). Pengaruh Lingkungan Kerja Dan Kompensasi Terhadap Kepuasan Kerja Karyawan PT Sinar Lentera Kencana Cikarang. Jurnal Pengembangan Wiraswasta,8(1), 1-20..

Murdani. (2012). Pengaruh Semangat dan Disiplin Kerja Terhadap Kinerja KAryawan Dept. HRD (Human Resource Development). PT. Pulp and Paper Pangkalan Kerinci. Skripsi. Pekanbaru: Fakultas Ekonomi dan Ilmu Sosial UIN Sultan Syarif.

Nasution, M. N. (2010). Manajemen Mutu Terpadu (Total Quality Manajemen). Bogor: Ghalia Indonesia.

Nitisemito. (2002). Manajemen Personalia Dan Manajemen Sumber Daya Manusia. Jakarta: Ghalia Indonesia.

Nugroho, Agung. (2005). Strategi Jitu Memilih Metode Statistik Penelitian Dengan SPSS. Yogyakarta: Andi.

Purwanto, Ngalim. (2010). Administrasi dan Supervisi Pendidikan. Bandung: Penerbit Remaja Rosdakarya.

Ramadanita dan Kasmiruddin. (2018). Pengaruh Kompensasi Dan Lingkungan Kerja Terhadap Kepuasan Kerja Karyawan Pada PT. Suka Fajar Pekanbaru. JOM FISIP, 5(1), 1-25.

Sarwoto. (2001). Dasar-Dasar Organisasi dan Manajamn. Jakarta: Ghalia Indonesia.

Siagian, Sondang P. (2007). Kepemimpinan Organisasi dan Perilaku Administrasi. Jakarta: Penerbit Gunung Agung.

Sugiyono. (2013). Metode Penelitian Pendidikan Pendekatan Kuantitatif, Kualitatif dan R\&D. Bandung: Penerbit Alfabeta.

Tenggara, Bram Aria. (2012). Hubungan Kepemimpinan Demokatik Dengan Semangat Kerja Karyawan Pada Perum Jamkrindo (Kantor Pusat). Skripsi. Depok: Fakultas Ilmu Sosial dan Politik Universitas Indonesia.

Tohardi, Ahmad. (2008). Pemahaman Praktis Manajemen Sumber Daya Manusia. Bandung: Mandar Maju.

Utama, M. (2007). Manajemen Sumber Daya Manusia. Denpasar: Universitas Udayana.

Yulhasari, Febrina Dewi. (2012). Pengaruh Kepemimpinan, Kompensasi dan Budaya Organisasi Terhadap Kepuasan Kerja Karyawan. Skripsi. Jakarta: Fakultas Ekonomi Universitas Gunadarma.

Yusnaena, Erdasti Husni. (2012). Pengaruh Kompensasi Non-Finansial Terhadap Kepuasan Kerja Karyawan Pada PT. HM. Sampoerna Tbk Area Padang. e-Jurnal Pelangi STKIP PGRI Sumbar. 4(2), 1-30.

Zainun Bukhori. (2007). Manajemen dan Motivasi. Jakarta: Bumi Aksara.

Pengaruh Lingkungan Kerja, Kompensasi Finansial dan Semangat Kerja Terhadap Keputusan Kerja Karyawan Pada PT. Usaha Gedung Mandiri Denpasar Bali 